\title{
A Comparison of 16S Ribosomal DNA Sequences from Five Isolates of Helicobacter pylori
}

\author{
BRUCE W. ECKLOFF, ${ }^{1}$ RAYMOND P. PODZORSKI, ${ }^{2}$ BRUCE C. KLINE, ${ }^{1 *}$ \\ AND FRANKLIN R. COCKERILL III ${ }^{2}$ \\ Department of Biochemistry and Molecular Biology, ${ }^{1}$ and Department of Laboratory Medicine, Section of \\ Clinical Microbiology, ${ }^{2}$ Mayo Clinic and Foundation, Rochester, Minnesota 55905
}

\begin{abstract}
Other workers have found that clinical isolates of Helicobacter pylori exhibit very extensive DNA sequence polymorphisms when they are examined by ribotyping or some other genomic sequence characterization technique. In fact, it is rare to find similar clones, much less identical ones, among isolates. We found that the levels of divergence between the $16 \mathrm{~S}$ ribosomal DNA sequences of individual organisms and the consensus sequence of the five isolates which we examined ranged from 0.2 to $0.5 \%$. In contrast, other workers have shown that levels of divergence between the 16S ribosomal DNA sequence of $H$. pylori and the 16S ribosomal DNA sequences of four other Helicobacter species range from 2.7 to $8.0 \%$. Our results show that the $H$. pylori $16 \mathrm{~S}$ ribosomal DNA is not very polymorphic and support the conclusion that $H$. pylori is a unique species.
\end{abstract}

Strains of Helicobacter pylori, the suspected agent of type B gastritis and gastric and duodenal ulcers, appear to exhibit high levels of genetic variability. The possibility that such variability occurs was suggested by the results of clonal analyses of 134 isolates by molecular techniques $(1,3,7,8,10)$. In the study of Taylor et al. (10), genomic DNAs from 20 isolates were examined for restriction fragment length polymorphism patterns and only two patterns matched. Perhaps more remarkably, the sizes of only a minority of the fragments matched. Similarly, Linton et al. (7) used ribotyping to show that none of the 12 strains that they examined were identical. These authors observed from 50 to $70 \%$ dissimilarity in fragment sizes. The results of these two studies are consistent with the results of Akopyanz et al. (1), who used random amplification of a single small primer to map the sequence sites in $H$. pylori genomes. In this study, 64 isolates were examined, and no 2 isolates gave the same pattern of amplicons. Again, the patterns of amplicon sizes were highly variable.

Beyond academic interests, several important, medically related questions are raised by these findings. One question concerns the utility of sequence information for identification. A second question is whether organisms clinically classified as $H$. pylori are correctly identified since the number of phenotypic parameters used in routine diagnostic examinations is limited. For example, any microaerophilic, gram-negative, curved organism that produces urease, oxidase, and catalase and is isolated from a human gut is classified as $H$. pylori. Might there be several species of human pathogens that fit this profile? We know that there are several Helicobacter species whose phenotypes fit this profile but are distinguished as separate species by other factors, and one of the major characteristics is $16 \mathrm{~S}$ ribosomal DNA sequence data (4).

Bacterial phylogeny and identification are coming to rest squarely on ribosomal sequence information. Thus, the third important question is whether the extensive polymorphism observed in genomic sequences and ribotypes of $H$. pylori extends to $16 \mathrm{~S}$ ribosomal DNA sequences and, if so, to what degree. To begin to answer to these questions, we amplified

* Corresponding author. Mailing address: Department of Biochemistry and Molecular Biology, Mayo Clinic and Foundation, 200 First Street, S.W., Rochester, MN 55905. Phone: (507) 284-2992. Fax: (507) 284-3383. and sequenced the $16 \mathrm{~S}$ ribosomal genes of five strains of $H$. pylori.

\section{MATERIALS AND METHODS}

Bacteria. Five isolates of $H$. pylori were examined. One isolate was strain ATCC 43504, and the other four isolates were clinical isolates recovered from endoscopic biopsies of patients evaluated at the Mayo Clinic in Rochester, Minn. The latter four isolates were designated MC123, MC268, MC903, and MC937. The nonidentity of the isolates was verified in our laboratories by Susan Wilkinson, who used pulsed-field gel electrophoresis performed as described by Taylor et al. (10) and genomic DNAs digested with NruI (data not shown).

DNA sequencing. Our sequencing strategy was to make $16 \mathrm{~S}$ amplicons from purified $H$. pylori DNA by using universal primers p246 and pH (Table 1) and the PCR. DNA was purified from approximately $5 \times 10^{8}$ cells in the exponential phase of growth by using phenol-chloroform extraction (9). Each $50-\mu \mathrm{l}$ PCR mixture contained $50 \mathrm{mM} \mathrm{KCl}, 10 \mathrm{mM}$ Tris (pH 8.3), $1.5 \mathrm{mM} \mathrm{MgCl} 2,200 \mu \mathrm{M}$ dATP, $200 \mu \mathrm{M}$ dCTP, 200 $\mu \mathrm{M}$ dGTP, $200 \mu \mathrm{M}$ dTTP, 50 pmol of each primer, $2.5 \mathrm{U}$ of Taq polymerase (Perkin-Elmer Cetus), and $1 \mu \mathrm{g}$ of extracted $H$. pylori DNA. The cycling conditions used were denaturation for $1 \mathrm{~min}$ at $94^{\circ} \mathrm{C}$, annealing for $2 \mathrm{~min}$ at $50^{\circ} \mathrm{C}$, and extension for $3 \mathrm{~min}$ at $72^{\circ} \mathrm{C}$ for 35 cycles, followed by a final extension for $10 \mathrm{~min}$ at $72^{\circ} \mathrm{C}$. An identical mixture lacking $H$. pylori target DNA was used as a negative control in each amplification experiment. The $16 \mathrm{~S}$ amplicons were purified by using PCR Magic Prep columns (Promega) according to the manufacturer's instructions. A 5- $\mu$ l portion of each purified amplicon was sequenced by using a dye terminator reagent kit, including Taq polymerase, and the protocol recommended by the manufacturer (Applied Biosystems, Inc., Foster City, Calif.); 3.2 pmol of sequencing primer was used per reaction mixture, and the cycling conditions used were denaturation at $96^{\circ} \mathrm{C}$ for $30 \mathrm{~s}$, annealing at $50^{\circ} \mathrm{C}$ for $15 \mathrm{~s}$, and extension for $4 \mathrm{~min}$ at $60^{\circ} \mathrm{C}$ for 25 cycles. The sequencing reaction products were separated from dye-labelled precursors by using Centri-Sep columns (Princeton Separations, Inc., Adelphia, N.J.) according to the manufacturer's instructions. The sequencing reaction products were then analyzed with a model 373A automated DNA sequencer (Applied Biosystems, Inc.).

Nucleotide sequence accession numbers. The nucleotide 
TABLE 1. H. pylori $16 \mathrm{~S}$ ribosomal DNA sequencing primers ${ }^{a}$

\begin{tabular}{|c|c|c|c|}
\hline Primer & & Sequence & Positions \\
\hline \multicolumn{4}{|c|}{ Forward primers } \\
\hline p246 & 5' AGA GTT TGA & TCC TGG CTC AG 3' & $8-27$ \\
\hline p170 & 5' TAA TAC CAG & ATA CTC . CT ACG G $3^{\prime}$ & $170-191$ \\
\hline p392 & $5^{\prime}$ GGA GGA TGA & AGG TTT TAG GAT $3^{\prime}$ & $392-412$ \\
\hline p548 & $5^{\prime}$ GGG ATA GTC & AGT CAG GTG TG 3' & $548-567$ \\
\hline p693 & $5^{\prime}$ CGA CCT GCT & GGA ACA TT $3^{\prime}$ & $693-709$ \\
\hline p903 & $5^{\prime}$ CGG TGG AGC & ATG TGG TTT AAT 3' & $903-923$ \\
\hline p1136 & $5^{\prime}$ TAA GGA GGA & GGA AGG TG $3^{\prime}$ & $1136-1152$ \\
\hline p1342 & $5^{\prime}$ AAT ACG TTC & CCG GGT CTT GT $3^{\prime}$ & $1342-1361$ \\
\hline \multicolumn{4}{|c|}{ Reverse primers } \\
\hline $\mathrm{p} 71 \mathrm{R}$ & $5^{\prime}$ CAT CGT TCG & ACT TGC ATG TA $3^{\prime}$ & $71-52$ \\
\hline p192R & $5^{\prime}$ CCC GTA .GG & AGT ATC TGG TAT $3^{\prime}$ & $192-172$ \\
\hline $\mathrm{p} 275 \mathrm{R}$ & 5' ATA CCC GTC & ATA GCC TTG GT $3^{\prime}$ & $275-256$ \\
\hline $\mathrm{p} 412 \mathrm{R}$ & $5^{\prime}$ ATC CTA AAA & ССТ ТСА ТСС ТС 3' & $412-393$ \\
\hline p663R & $5^{\prime}$ TAC GGA TTT & TAC CCC TAC AC $3^{\prime}$ & $663-644$ \\
\hline p1073R & $5^{\prime}$ TCG TTG CGG & GAC TTA ACC CAA $3^{\prime}$ & $1073-1053$ \\
\hline p1392R & $5^{\prime}$ ATG GTG TGA & CGG GCG GT' AG $3^{\prime}$ & $1382-1363$ \\
\hline $\mathrm{pH}$ & 5' AAG GAG GTG & ATC CAG CCG CA $3^{\prime}$ & $1484-1503$ \\
\hline
\end{tabular}

${ }^{a}$ Primers p246 and pH are universal 16S ribosomal DNA primers taken from the study of Edwards et al. (5). The periods in primers p170 and p192R represent inadvertent deletion of a $\mathrm{C}$ in the oligonucleotides compared with the sequence shown in Fig. 1. Despite the deletion, the primers worked effectively. The positions of the primers refer to the sequence numbers used in Fig. 1.

sequences of the isolates which we used have been deposited in the GenBank data base under the following accession numbers: strain MC123, U01328; strain MC238, U01329; strain ATCC 43504, U01330; strain MC937, U01331; and strain MC903, U01332. The $H$. pylori ATCC 43504 sequence determined by Eaton et al. (4) was deposited in the GenBank data base under accession number M88157, and the sequences of the seven strains studied by Höök-Nikanne et al. (6) were deposited in the GenBank data base under accession numbers M55303 to M55309.

\section{RESULTS AND DISCUSSION}

H. pylori has been reported to contain three copies of the $16 \mathrm{~S}$ ribosomal gene (10); we did not determine the numbers of copies in the isolates which we studied. To sequence the $16 \mathrm{~S}$ ribosomal genes, we used universal PCR primers and genomic DNA to produce amplicons. The amplicons were then partially purified and sequenced by using dye-labelled dideoxy terminators, the Sanger technique, and an automated sequencer. Within the sensitivity of this method, all of the copies that were amplified appeared to be identical because we did not detect peaks that were obvious mixtures of bases. A possible exception was at position 1434 , as discussed below.
Figure 1 shows the consensus sequence determined for the five isolates. The sequence of each individual isolate can be deduced by altering the consensus sequence at the positions indicated in Table 2 . As Table 2 shows, deviations from the consensus sequence were found at 13 separate positions. The number of deviations from the consensus sequence were two (strains ATCC 43504 and MC930), three (strains MC123 and MC937), and five (strain MC268). We found that strains MC123 and MC43504 share a common variation, a $\mathrm{C} \rightarrow \mathrm{T}$ transition at position 1105, while strains MC903 and MC937 also share a common variation, an $A \rightarrow G$ transition at position 993. Since each of these strains has only two or three differences, the sharing of a common change suggests a clonal origin. However, more information concerning these isolates is needed before firm conclusions can be drawn. Table 2 also shows that the majority of variation occurs from about position 801 to position 1419; that is, $69 \%$ of the variation occurs in the 3 ' one-half of the gene. The variation that occurs in the 5 ' end of the gene is clustered between positions 91 and 95 . Of the 13 variants, 11 represent transitions; the change at 95 is a $\mathrm{T} \rightarrow \mathrm{G}$ transversion, and the change at position 92 is a single-base deletion.

The 16S ribosomal DNA sequence of $H$. pylori ATCC 43504 is $97.4 \%$ identical to the sequence of Helicobacter acinonyx;

TABLE 2. 16S ribosomal DNA sequence differences in five $H$. pylori strains

\begin{tabular}{|c|c|c|c|c|c|c|c|c|c|c|c|c|c|c|c|c|c|c|}
\hline \multirow{2}{*}{ Strain } & \multicolumn{13}{|c|}{ Base at position: } & \multirow{2}{*}{$\begin{array}{l}\text { No. of } \\
\text { differences } \\
\text { compared } \\
\text { with } \\
\text { consensus } \\
\text { sequence }\end{array}$} & \multicolumn{4}{|c|}{$\begin{array}{l}\text { No. of differences compared with } \\
\text { sequence of strain: }\end{array}$} \\
\hline & 91 & 92 & 94 & 95 & 801 & 993 & 1000 & 1105 & 1235 & 1245 & 1259 & 1411 & 1419 & & MC123 & $\begin{array}{r}\text { ATCC } \\
43504\end{array}$ & MC903 & MC937 \\
\hline MC123 & & & & & & & & $\mathrm{T}$ & & & & A & & 2 & & & & \\
\hline ATCC 43504 & $\mathrm{G}$ & & & & & & & $\mathbf{T}$ & $\mathrm{T}$ & & & & & 3 & 3 & & & \\
\hline МC903 & & & & & & $\mathrm{G}$ & & & & $\mathrm{T}$ & & & & 2 & 4 & 5 & & \\
\hline MC937 & & & & & A & $G$ & $\mathrm{C}$ & & & & & & & 3 & 5 & 6 & 3 & \\
\hline $\mathrm{MC} 268$ & & $\Delta^{a}$ & $\mathrm{~T}$ & $\mathrm{G}$ & & & & & & & $\mathrm{G}$ & & A & 5 & 7 & 8 & 7 & 8 \\
\hline Consensus & A & $\mathrm{T}$ & $\mathrm{C}$ & $\mathrm{T}$ & $\mathbf{G}$ & $\mathrm{A}$ & $\mathrm{T}$ & $\mathrm{C}$ & $\mathrm{C}$ & $\mathrm{C}$ & A & G & G & & & & & \\
\hline
\end{tabular}

${ }^{a} \Delta$, deletion. 
1 ITTATGGAGA GITTGATCCT GGCTCAGAGT GAACGCTGGC GGCGTGCCTA

51 ATACATGCAA GTCGAACGAT GAAGCTTCTA GCTTGCTAGA ATGCTGATTA

101 GTGGCGCACG GGTGAGTAAC GCATAGGTCA TGTGCCTCTT AGTTTGGGAT

151 AGCCATTGGA AACGATGATT AATACCAGAT ACTCCCTACG GGGGAAAGAT

201 TTATCGCTAA GAGATCAGCC TATGTCCTAT CAGCTTGTTG GTAAGgTAAT

251 GGCTTACCAA GGCTATGACG GGTATCCGGC CTGAGAGGGT GAACGGACAC

301 ACTGGAACTG AGACACGGTC CAGACTCCTA CGGGAGGCAG CAGTAGGGAA

351 TATTGCTCAA TGGGGGAAAC CCTGAAGCAG CAACGCCGCG TGGAGGATGA

401 AGGTTTTAGG ATTGTAAACT CCTTITGTTA GAGAAGATAA TGACGGTATC

451 TAACGAATAA GCACCGGCTA ACTCCGTGCC AGCAGCCGCG GTAATACGGA

501 GGGTGCAAGC GTTACTCGGA ATCACTGGGC GTAAAGAGCG CGTAGGCGGG

551 ATAGTCAGTC AGgTGTGAAA TCCTATGGCT TAACCATAGA ACTGCATTTG

601 AAACTACTAT TCTAGAGTGT GGGAGAGGTA GGTGGAATTC TTGGTGTAGG

651 GGTAAAATCC GTAGAGATCA AGAGGAATAC TCATTGCGAA GGCGACCTGC

701 TGGAACATTA CTGACGCTGA TTGCGCGAAA GCGTGGGGAG CAAACAGGAT

751 TAGATACCCT GGTAGTCCAC GCCCTAAACG ATGGATGCTA GTTGTTGGAG

801 GGCTTAGTCT CTCCAGTAAT GCAGCTAACG CATTAAGCAT CCCGCCTGGG

851 GAGTACGGTC GCAAGATTAA AACTCAAAGG AATAGACGGG GACCCGCACA

901 AGCGgTGGAG CATGTGGITT AATTCGAaGA TACACGAAGA ACCTTACCTA

951 GGCTTGACAT TGAGAGAATC CGCTAGAAAT AGTGGAGTGT CTAGCTTGCT

1001 AGACCTTGAA AACAGGTGCT GCACGGCTGT CGTCAGCTCG TGTCGTGAGA

1051 TGTTGGGTTA AGTCCCGCAA CGAGCGCAAC CCCCTTTCTT AGTTGCTAAC

1101 AGGTCATGCT GAGAACTCTA AGGATACTGC CTCCGTAAGG AGGAGGAAGG

1151 TGGGGACGAC GTCAAGTCAT CATGGCCCTT ACGCCTAGGG CTACACACGT

1201 GCTACAATGG GGTGCACAAA GAGAAGCAAT ACTGCGAAGT GGAGCCAATC

1251 TTCAAAACAC CTCTCAGTTC GGATTGTAGG CTGCAACTCG CCTGCATGAA

1301 GCTGGAATCG CTAGTAATCG CAAATCAGCC ATGTTGCGGT GAATACGTTC

1351 CCGGGTCTTG TACTCACCGC CCGTCACACC ATGGGAGTTG TGTTTGCCTT

1401 AAGTCAGGAT GCTAAATTGG CTACTGCCCA CGGCACACAC AGCGACTGGG

1451 GTGAAGTCGT AACAAGGTAA CCGTAGGTGA ACCIGCGGCT GGATCACCTC

1501 CTT

FIG. 1. Consensus sequence of $H$. pylori $16 \mathrm{~S}$ ribosomal DNA. This sequence represents a compilation of the data for the five isolates discussed in the text and shown in Table 2 plus the data for the GenBank accession number M88157 sequence deposited by Eaton et al. (4). The strain ATCC 43504 sequence and the GenBank accession number M88157 sequence are the same, as described in the text. The sequences of all of the isolates are identical to the consensus sequence except as indicated in Table 2. The numbers begin as described by Brosius et al. (2) for the Escherichia coli $16 \mathrm{~S}$ ribosomal gene. We determined the sequences for all isolates on both strands in their entirety except for the region from position 1327 to position 1378; for this region we could determine the sequence for only one strand. However, our sequence agrees perfectly with the sequence of Eaton et al. (4). The forward and reverse PCR primers (primers $\mathrm{p} 246$ and $\mathrm{pH}$ ) are underlined. The portion of the sequence in boldface type is new data

that is, the two sequences differ at almost 30 positions (4). It is interesting that because of mutations at positions 91,94 , and 95 strain MC268 has the same sequence as $H$. acinonyx (that is, AGAAGTGGA). Also, the mutation at position 1419 in strain MC268 changes a $\mathrm{G}$ to an A. A is also found at position 1419 in $H$. acinonyx. Thus, four of the five differences between the strain MC268 sequence and the consensus sequence are found in $H$. acinonyx. However, $H$. acinonyx still differs from strain MC268 at approximately 25 other positions.

Our results are largely in agreement with those of Eaton et al., whose unpublished $H$. pylori ATCC 43504 sequence has been deposited in the GenBank data base. These authors used rRNA and reverse transcriptase to make single-stranded DNA for sequencing. Our sequence differs from the sequence of Eaton et al. at two locations; $\mathrm{C}$ is missing from the sequence of Eaton et al. at our position 184, and we found a $G$ at our position 727, whereas Eaton et al. found a T. The results of a reexamination by Eaton et al. of their raw data suggest that our results are correct ( $3 a$ ). In various experiments we observed an A or $\mathrm{C}$ at our position 1434, but Dewhirst and colleagues (3b) have shown that there is always a $\mathrm{C}$ at this position in Helicobacter species.

Previously, Höök-Nikanne et al. (6) sequenced 397 bp of $16 \mathrm{~S}$ RNAs of seven $H$. pylori strains isolated on three continents. The region which these authors sequenced corresponds to our coordinates 71 to 468 (Fig. 1). We examined the data of Höök-Nikanne et al. (which have been deposited in the GenBank data base) and compared their results with to our results. The data agreed completely with the following exceptions: (i) like Eaton et al., Höök-Nikanne et al. did not find $\mathrm{C}$ at position 184; (ii) at position 71 we found only $G$, and Höök-Nikanne et al. found only $C$; and (iii) Höök-Nikanne et al. reported three single-base-pair differences from the consensus sequence in two strains, at positions $91(\mathrm{~T} \rightarrow \mathrm{G}), 129(\mathrm{C}$ $\rightarrow \mathrm{T})$, and $463(\mathrm{~A} \rightarrow \mathrm{T})$. We also found a change at position 91 in one strain; however, the change which we found was a deletion (Table 2).

In addition to the differences between our results and those of other workers, we were able to identify the unknown bases in GenBank sequence M88157 at our positions 913, 928 to 931, and 1084 (Fig. 1). Moreover, we also sequenced an additional $30 \mathrm{bp}$ at the $3^{\prime}$ end of the 16S DNA sequence (Fig. 1, boldface type) beyond the bases reported in GenBank sequence M88157 even though we examined an additional $50 \mathrm{bp}$; we did not count the last $20 \mathrm{bp}$ because this region represented primer $\mathrm{H}$, which was used to make the amplicon.

The results of a large number of studies have established the utility and validity of microbial phylogeny based on 16S DNA sequence data (see reference 11 for a review). For the most part, 16S DNA sequence data represent sequence information obtained from a single isolate of a species. Indeed, this type of data base should be useful for clinical laboratories as well. However, the following immediate questions occur: to what extent do clinical specimens deviate from the data base entry, and how much deviation is acceptable? Our results address the first question but not the second.

Deviation can be assessed by comparison with a type strain, by pairwise comparisons (Table 2), or by comparison with a consensus sequence (Table 2). While each of these approaches has its merits, comparison with a consensus sequence minimizes disparity and avoids distortion due to selection of an arbitrary standard. Presumably, the consensus sequence is closer to the $H$. pylori ancestral sequence than the sequence of any given isolateis. Since the sample size in this study was small (five isolates), we doubt that our $H$. pylori consensus sequence is the final one. In fact, partial sequencing results for an additional five isolates indicated that $A$ and $G$ occur equally at our position 91 . Thus, the consensus sequence seems to have a purine at this position. Our results clearly establish that $16 \mathrm{~S}$ ribosomal DNA sequences in $H$. pylori are relatively stable and that the high level of genomic variability ascribed to this 
organism does not extend to the $16 \mathrm{~S}$ ribosomal genes. Indeed, the sequences of the five $H$. pylori strains differ from the consensus sequence by no less than $0.2 \%$ and no more than $0.5 \%$; in contrast, five Helicobacter species, including $H$. pylori, $H$. acinonyx, Helicobacter felis, Helicobacter mustalae, and Helicobacter muridarum, differ in their 16S ribosomal DNA sequences by 2.7 to $8.0 \%$ (4). Thus, our data support the notion $H$. pylori is a separate species. Finally, we raised the possibility above that the morphological and physiological parameters used clinically to isolate and identify $H$. pylori might not be as discerning as molecular data. Thus far, our results do not support this possibility.

\section{ACKNOWLEDGMENTS}

We are deeply indebted to Floyd Dewhirst for his helpful discussions and generous sharing of data; his many kindnesses are highly appreciated. We also thank Susan Wilkinson for characterizing the Mayo Clinic $H$. pylori genomic restriction polymorphisms by pulsed-field gel electrophoresis.

\section{REFERENCES}

1. Akopyanz, N., N. O. Bukanov, T. U. Westblom, S. Kresovich, and D. E. Berg. 1992. DNA diversity among clinical isolates of Helicobacter pylori detected by PCR-based RAPD fingerprinting. Nucleic Acids Res. 20:5137-5142.

2. Brosius, J., M. L. Palmer, P. J. Kennedy, and H. F. Noller. 1978. Complete nucleotide sequence of a 16S ribosomal RNA gene from Escherichia coli. Proc. Natl. Acad. Sci. USA 75:4801-4805.

3. Clayton, C. L., H. Kleanthous, D. D. Morgan, L. Puckey, and S. Tabaqchali. 1993. Rapid fingerprinting of Helicobacter pylori by polymerase chain reaction and restriction fragment length polymorphism analysis. J. Clin. Microbiol. 31:1420-1425.

3a.Dewhirst, F. E. Personal communication.

3b.Dewhirst, F. E., K. A. Eaton, and S. Paster. Personal communication.

4. Eaton, K. A., F. E. Dewhirst, M. J. Radin, J. G. Fox, B. J. Paster, S. Krakowka, and D. R. Morgan. 1993. Helicobacter acinonyx sp. nov., isolated from cheetahs with gastritis. Int. J. Syst. Bacteriol. 43:99-106.

5. Edwards, U., T. Rogall, H. Blöcker, M. Emde, and E. C. Böttger. 1989. Isolation and direct complete nucleotide determination of entire genes. Characterization of a gene coding for $16 \mathrm{~S}$ ŕrbosomal RNA. Nucleic Acids Res. 17:7843-7853.

6. Höök-Nikanne, J., M.-L. Solin, T. U. Kosunen, and M. Kaartinen. 1991. Comparison of partial 16S rRNA sequences of different Helicobacter pylori strains, Helicobacter mustelae and a gastric campylobacter-like organism (GCLO). Syst. Appl. Microbiol. 14: 270-274.

7. Linton, D., M. Moreno, R. J. Owen, and J. Stanley. 1992. 16S rrn gene copy number in Helicobacter pylori and its application to molecular typing. J. Appl. Bacteriol. 73:501-506.

8. Moore, R. A., A. Kureishi, S. Wong, and L. E. Bryan. 1993. Categorization of clinical isolates of Helicobacter pylori on the basis of restriction digest analyses of polymerase chain reactionamplified ure C genes. J. Clin. Microbiol. 31:1334-1335.

9. Sambrook, J., E. F. Fritsch, and T. Maniatis. 1989. Molecular cloning: a laboratory manual, 2nd ed. p. Append E.3. Cold Spring Harbor Laboratory Press, Cold Spring Harbor, N.Y.

10. Taylor, D. E., M. Eaton, N. Chang, and S. M. Salama. 1992. Construction of Helicobacter pylori genome map and demonstration of diversity at the genome level. J. Bacteriol. 174:6800-6806.

11. Woese, C. R. 1987. Bacterial evolution. Microbiol. Rev. 51:221271. 